\title{
Biochar efficiency in copper removal from Haplic soils
}

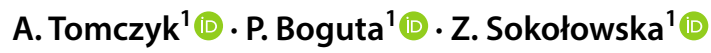

Received: 21 November 2018 / Revised: 9 January 2019 / Accepted: 14 January 2019 / Published online: 28 January 2019

(c) The Author(s) 2019, corrected publication 2019

\begin{abstract}
The main aim of the study was to examine the biochar efficiency in copper $(\mathrm{Cu})$ ion removal from Haplic (Luvisol, Podzol) soils. In other words, the most effective biochar dose and the most favorable environment $\mathrm{pH}$ value were proposed. The copper removal was carried out based on the adsorption process. The results of kinetics measurements were modeled using Richie equation, whereas the adsorption isotherms using Langmuir-Freundlich and Dubinin-Radushkevich equations. The copper removal is a strongly $\mathrm{pH}$-dependent process which is associated with variability of chemical $\mathrm{Cu}$ forms and various reactivities of organic molecules. The $\mathrm{Cu}$ adsorption amount was higher on silty Haplic Luvisol than on sandy Haplic Podzol mainly due to higher content of organic carbon, functional groups, clay and silt fractions as well as larger surface area. Moreover, the biochar addition increased linearly the soil surface charge and contributed to higher copper adsorption in the whole range of investigated ion concentrations. The higher the biochar dose added, the more $\mathrm{Cu}$ ions were adsorbed.
\end{abstract}

Keywords Copper removal $\cdot \mathrm{pH}$ condition $\cdot$ Biochar $\cdot$ Haplic soil

\section{Introduction}

Copper $(\mathrm{Cu})$ is a heavy metal found in soils mostly in the form of sulfides, sulfates and carbonates. Depending on environmental conditions like $\mathrm{pH}$, ionic strength, temperature, concentration and molecular weight of organic particles contained in soil, $\mathrm{Cu}$ may be in soluble or insoluble form (Aydin and Bulut 2008; Pendias and Kabata-Pendias 1999). Cu can also form strongly bonded complexes with soil organic matter and clay minerals. What is more, under less-favored conditions, $\mathrm{Cu}$ may be released in uncontrolled way and pollute soil environment due to its toxic effect (Aman et al. 2008).

Different methods and technologies have been used to remove heavy metals from soils, ground water and sewages. Probably, the cheapest and the most effective methods are based on adsorption (sorption) processes occurring on the natural or synthetic adsorbents (Chen et al. 2011; Gupta et al. 2009; Zhang et al. 2014, 2017; Liu et al. 2017a).

Editorial responsibility: M. Abbaspour.

A. Tomczyk

atomczyk@ipan.lublin.pl

1 Institute of Agrophysics, Polish Academy of Sciences, Doświadczalna 4, 20-290 Lublin, Poland
Among different adsorbents (sorbents), biochars and other carbon adsorbents belong to the most perspective materials (Ahmad et al. 2014; Mohan and Pitmann 2006; Gupta and Nayak 2012; Wang et al. 2018; Duan et al. 2017). They can be obtained at much lower energy expenses than active carbon (Xu et al. 2016). Biochars are synthesized by pyrolysis of biomass (wastes and sludges) in a low-oxygen environment (Karami et al. 2011; Uchimiya et al. 2011a). The obtained material is fine-grained, rich in carbon, stable and exhibits high specific surface area, marginal toxicity and high bio-degradability (Malińska 2012).

The above features decide that biochars can be concerned as amendments improving physicochemical properties of soils and, simultaneously, reducing the pollutants biotoxicity (Alburquerquel et al. 2014; Mohamed et al. 2017; Liu et al. $2017 b$ ). The efficiency in contamination removal depends on sorbent-specific surface area and cation exchange capacity (Ahmad et al. 2014; Kołodyńska et al. 2012). The interfering ions, solution $\mathrm{pH}$ and biochar dose (Bogusz et al. 2015; Kilic et al. 2013) are also important factors. Depending on biochar properties, the strength and direction of changes in soil processes observed after its addition may be varied (Sigua et al. 2016). Some reports have shown that biochar not only does act as a soil conditioner increasing soil cation capacity, but may also act as a low-grade fertilizer (Novak et al. 2009). However, some scientists reported that addition of 
biochar may lead to soil pollution (PAHs, heavy metals, etc.) (Soudek et al. 2017). The above ambiguous opinions force to perform the further research on the impact of biochar on sorption capabilities relative to heavy metals present in soil.

Therefore, the main aim of this paper was to study $\mathrm{Cu}$ adsorption process (kinetics and equilibrium) on soils modified with different biochar doses. In this way, the efficiency of biochar in $\mathrm{Cu}$ removal from the above soil was determined. To provide valuable results, we describe experimental kinetic data by the second-order Ritchie equation (Ritchie 1977) and the equilibrium isotherms by Langmuir-Freundlich and Dubinin-Radushkevich equations (Kumar and Bandyopadhyay 2006; Sokołowska and Sokołowski 2011; Veli and Alyuz 2007). The combination of experimental data with theoretical models showed differences between process of metal adsorption on different soils containing various concentrations of biochar as well as under various $\mathrm{pH}$ conditions. Owing to it, the most efficient dose of biochar in $\mathrm{Cu}$ removal from the selected soils and the most favorable $\mathrm{pH}$ conditions for this process were proposed. It is also worth mentioning that the effects of organic and inorganic compounds on the $\mathrm{Cu}$ adsorption process were considered and the impact of biochar on the soil surface properties was also described. Such a comprehensive approach to the issue makes this paper innovative and of great environmental importance. It refers to a worldwide problem with heavy metal soil pollution. The developing industry generates a lot of waste containing heavy metals, which contributes to soil degradation. The use of biochar is an opportunity to improve the condition of the soil environment. The immobilization of heavy metals by the adsorption process makes them inaccessible to organisms and, as a result, their toxic effect is limited.

\section{Materials and methods}

\section{Materials}

The experiments were carried out by using two type of soils: Haplic Podzol (developed from loamy sands) and Haplic Luvisol (developed from loess material), which were taken from the A-horizon $(0-20 \mathrm{~cm})$ in the locations of Sobieszyn $\left(51^{\circ} 35^{\prime} \mathrm{N}, 22^{\circ} 9^{\prime} \mathrm{E}\right)$ and Felin $\left(51^{\circ} 13^{\prime} \mathrm{N}, 22^{\circ} 38^{\prime} \mathrm{E}\right)$ in Poland, respectively. Soils were air-dried, crushed and sieved through the sieve of 1-mm meshes. The main properties of the soils were investigated by conventional methods: the distribution of size fractions was estimated from aerometric method of Casagrande modified by Prószyński (PN-R04032 1998); the $\mathrm{pH}$ value was measured electrochemically in $\mathrm{H}_{2} \mathrm{O}$ and $1 \mathrm{M} \mathrm{KCl}$ using a digital $\mathrm{pH}$ meter (Radiometer Copenhagen); the ash content $(A)$ was calculated by weighing the residue after $5 \mathrm{~h}$ of combustion at $550{ }^{\circ} \mathrm{C}$ in a muffle furnace (FCF 12 SP, Czylok); the content of $\mathrm{Cu}$ was determined from atomic absorption spectrometry (ContrAA 300, Analytik Jena); in turn, the bulk density $(d)$ was determined by the pycnometric method (ultrapycnometer 1000, Quantachrome). The total carbon content $\left(\mathrm{C}_{\text {tot }}\right.$. $)$ was evaluated via $C / N$ analyzer (TOC MULTI N/C 2000, Analytik Jena), whereas the total content of organic carbon $\left(C_{\text {org. }}\right)$ by Alten's method (Hoffmann et al. 2012) with a ratio 1:500 of sample to $\mathrm{K}_{2} \mathrm{CrO}_{7}$ solution. The total variable surface charge was established by potentiometric titration with Titrino 702 SM (Metrohm) (Jozefaciuk 2002), and the amount of lactonic, basic, carboxylic, phenolic groups was calculated by Boehm method (Boehm 2002). The soil surface area $\left(S_{\mathrm{BET}}\right)$ was designated from the water vapor adsorption/desorption isotherm method according to the Polish standard (PN-Z19019-1 1997).

Biochar, used in the experiment, is the commercial product-Biochar FLUID made by FLUID S.A. Company (Poland). The biochar was produced during the wood waste pyrolysis process at high temperature $\left(650^{\circ} \mathrm{C}\right)$. The following parameters of the sorbent: $\mathrm{pH}$ in $\mathrm{H}_{2} \mathrm{O}$ and $1 \mathrm{M} \mathrm{KCl}, \mathrm{Cu}$ content, density, ash, total and organic carbon content, surface area, total variable surface charge and quantitative and qualitative analysis of functional groups, were measured by the same methods and were as in case of soils. The particle size of biochar was $2 \mathrm{~mm}$.

Three replications were performed for each analysis. The results were averaged and are presented in Tables 1 and 2 for soils and biochar, respectively.

\section{Batch adsorption experiment}

The samples containing a constant amount of the soil and different weight percent of biochar $(0.01,0.1 \%$ for kinetics and 0 , $0.01,0.05,0.1 \%$ for equilibrium measurements) were prepared in the following way. The amount of $100 \mathrm{ml}$ of the $\mathrm{Cu}$ solution was added to $20 \mathrm{~g}$ of the soil sample with different biochar additions. The initial concentration of $\mathrm{Cu}\left(\mathrm{CuCl}_{2} \cdot 2 \mathrm{H}_{2} \mathrm{O}\right)$ in the solutions was $10 \mathrm{mg} / \mathrm{l}$ for kinetics and $0,0.4,2,6,10,20$, $30,40 \mathrm{mg} / \mathrm{l}$ for equilibrium measurements. $\mathrm{Cu}$ concentration for kinetics studies was chosen on the basis of earlier author's research (common values in soil environment, reasonable changes in kinetic curves). The samples with solution were permanently mixed with a magnetic stirrer under constant $\mathrm{pH}$ conditions. The $\mathrm{pH}$ value ( 6.5 for kinetics and 3,5 or 6.5 in the case of equilibrium measurements) was automatically adjusted by adding $0.1 \mathrm{M} \mathrm{HCl}$ or $\mathrm{NaOH}$ solution, if necessary. Contact time in kinetics studies ranged from 0 to $180 \mathrm{~min}$. After $\mathrm{Cu}$ adsorption on soil modified by various dose of biochar, the solutions were filtered and the $\mathrm{Cu}$ concentration was measured by an AAS apparatus. On the basis of kinetics experiments, it was stated that $3 \mathrm{~h}$ was sufficed for the establishing adsorption 
equilibrium. All samples were three times repeated, and the points of graphs were obtained from the average.

The amount of adsorbed heavy metal $(A)$ per unit mass of absorbent was calculated as follows:

$A=\frac{\left(C_{0}-C_{\mathrm{e}}\right) \cdot V}{m}$

where $C_{0}$ is the initial concentration of heavy metal, $C_{\mathrm{e}}$ the concentration of heavy metal at equilibrium $(\mathrm{mg} / \mathrm{l}), m$ the mass of sample (mg) and $V$ the volume of solution (1).

Besides experiments with $\mathrm{Cu}$, specific surface area of the initial soils and soils modified with biochar was determined by applying the BET method and the isotherms of water vapor adsorption at $298 \mathrm{~K}$ (Sokołowska et al. 1993; Sokołowska 2011), and for the extended concentrations of biochar: $0 \leq p \leq 10 \%$. All the measurements were repeated three times at the temperature of $T=298 \mathrm{~K}$ and then averaged.

A part of organic matter from the samples can dissolve in the solution during adsorption process. Thus, after adsorption experiments, the filtrates were analyzed on multi-N/C 2000 apparatus with the aim of the determination of the content of organic carbon in solutions.

\section{Modeling}

\section{Kinetics}

Among different models reported in the literature (Ho 2006a) that have been employed to describe kinetics of ions adsorption, the second-order Ritchie theory (Ritchie 1977) was selected. In this theory:

$\theta=N(t) / N_{\infty}$

where $N(t)$ is the amount of adsorbed the soil with various additives of biochar at time $t, N_{\infty}$ the amount of adsorbed at equilibrium and $\theta$ the fraction of surface sites which are occupied by adsorbed species. Moreover, $n$ is the number of surface sites occupied by each ion and $\alpha$ is the constant of rate. If the rate of adsorption depends solely on the fraction of sites which are unoccupied at time $t$, then

$\frac{\mathrm{d} \theta}{\mathrm{d} t}=\alpha(1-\theta) n$

For divalent ions, it is reasonable to assume that $n=2$; then, the integrated form of Eq. (3) becomes

$(1-\theta)^{-1}=1+\alpha t$

The linear form of Eq. (4) reads

$y=\frac{t}{N(t)}=b+a t, \quad b=\frac{1}{\alpha N_{\infty}}, \quad a=\frac{1}{N_{\infty}}$ 
Table 2 Functional groups in the soils and biochar samples

\begin{tabular}{lllllll}
\hline Sample & $\begin{array}{l}\text { Basic } \\
\text { groups } \\
(\mathrm{cmol} / \mathrm{kg})\end{array}$ & $\begin{array}{l}\text { Lactonic } \\
\text { groups }(\mathrm{cmol} / / \\
\mathrm{kg})\end{array}$ & $\begin{array}{l}\text { Phenolic } \\
\text { groups }(\mathrm{cmol} / \\
\mathrm{kg})\end{array}$ & $\begin{array}{l}\text { Carboxylic } \\
\text { groups }(\mathrm{cmol} / \\
\mathrm{kg})\end{array}$ & $\begin{array}{l}\text { Acidic } \\
\text { groups } \\
(\mathrm{cmol} / \mathrm{kg})\end{array}$ & $\begin{array}{l}\text { Total } \\
\text { groups } \\
(\mathrm{cmol} / \mathrm{kg})\end{array}$ \\
\hline Haplic Luvisol & 1.37 & 4.13 & 1.00 & 3.13 & 8.25 & 9.62 \\
Haplic Podzol & 1.25 & 1.56 & 0.89 & 1.00 & 3.45 & 4.70 \\
Biochar & 531 & 165 & 228 & 18.0 & 411 & 942 \\
\hline
\end{tabular}

Thus, the plot of $y$ versus $t$ allows for the determination of the parameters $N_{\infty}$ and $\alpha$ from the straight line slope and its intercept.

\section{Equilibrium adsorption isotherms}

Natural soil sorbents are highly heterogeneous. Among the factors responsible for that heterogeneity, the most important are the nature of chemical complex and the irregularities of the physical structure. Consequently, the fit of experimental ion adsorption data to the equations developed for models that neglect surface heterogeneity is usually poor and gives no information concerning the adsorption mechanism. This fact is commonly accepted and hence in several works, devoted to the problem of ion sorption by soils; various models of adsorption on heterogeneous surfaces have been considered (Sokołowska and Sokołowski 2008, 2011). The general equation for the overall adsorption isotherm has the following form

$\frac{A}{A_{m}}=\int \mathrm{d} \varepsilon \theta_{l}(c, \varepsilon) \chi(\varepsilon)$,

where $A$ is the amount of adsorber species at a given bulk concentration, $c, A m$ the capacity of adsorption, $\theta_{l}$ the socalled local adsorption isotherm which describes the adsorption equilibrium on a given kind of adsorption centers and $\chi(\varepsilon)$ the function describing the distribution of adsorption centers with respect to the energy parameter $\varepsilon$. According to the last equation, the evaluation of the overall adsorption isotherm requires knowledge of two functions: $\theta_{l}$ and $\chi(\varepsilon)$.

In particular, if the local adsorption equilibrium obeys the model of Langmuir

$\theta_{l}=\frac{K(\varepsilon) c}{[1+K(\varepsilon) c]}$

(where the constant $K(\varepsilon)$ is a function of the energy of adsorption), assuming different analytical forms of $\chi(\varepsilon)$, different analytical equations for overall adsorption isotherm can be obtained (Jaroniec and Madey 1988; Jeppu and Clement 2012; Sokołowska et al. 1988). Since the aim of this work is not to present theoretical considerations, but to concentrate on practical issues that aimed at the finding models accurately describing experimental adsorption isotherms.
The so-called generalized Langmuir-Freundlich equation corresponds to Gaussian-like energy distribution function and has the form (Marczewski et al. 1986; Peereboom 2007)

$\frac{A}{A_{m}}=\left\{\frac{\left(K_{\mathrm{LF}} c\right)^{m}}{\left[1+\left(K_{\mathrm{LF}} c\right)^{m}\right]}\right\}^{\frac{n}{m}}$

In the above equation, $n$ and $m(0<n, m \leq 1)$ are parameters determining the shape of the energy distribution function. The case of $n=1$ has been the most frequently studied (Jeppu and Clement 2012). For this particular case, the determination of the constants of Eq. (8) can be carried out by quasi-linear regression method. For a fixed value of $m$, the following linear form

$\left(\frac{c}{A}\right)^{m}=\left(\frac{1}{A_{m} K_{\mathrm{LF}}}\right)^{m}+\left(\frac{c}{A_{m}}\right)^{m}$.

can be used to describe experimental data.

The overall adsorption isotherms in Eqs. (8) and (9) correspond to the situation in which the distribution functions of adsorption centers exhibit single maxima. Several adsorbents, however, are characterized by highly differentiated heterogeneous surfaces. In order to describe a multi-maximum distribution, several approaches were proposed (Jaroniec and Madey 1988). One of the most popular approaches is based on the use of the so-called generalized isotherm of Dubinin-Radushkevich (Sokołowska and Sokołowski 2008, 2011).

$\frac{A}{A_{m}}=\exp \left[\sum_{j=1}^{k} B_{j}\left(\ln \left(\frac{c}{C_{m}}\right)\right)^{j}\right]$,

where $B_{j}$ and $C_{m}$ are the parameters. If all, but $B_{2}$ coefficients are equal zero, Eq. (10) reduces to the well-known isotherm of Dubinin-Radushkevich that corresponds to the Gaussian energy distribution. For an increasing number of nonzero coefficients $B_{j}$, the function of distribution energy can exhibit more and more maxima. The evaluation of the parameters of Eq. (10) can be carried out by employing a polynomial regression method to experimental data of $\ln (a)$ versus $\ln (c)$. It notes that the degree of the polynomial in the exponent of Eq. (10) can be also treated as the best-fit 
parameter. Detailed description of the method of fitting Eq. (10) to experimental data was described by Jaroniec and Bräuer (1986).

\section{Results and discussion}

\section{Physicochemical properties of soils and biochar}

The results in Tables 1 and 2 reveal different physicochemical properties of the soils and biochar samples. Haplic Luvisol belongs to neutral, silty soils with weak sand content, whereas Haplic Podzol is acidic sandy soil. Haplic Luvisol shows higher value of surface area as well as slightly higher content of total and organic carbon compared to Haplic Podzol. Despite these differences, it should be emphasized that both soils are poor in organic carbon, which makes them poorly suited for crops. The concentration of $\mathrm{Cu}$, density and ash content are similar for both soils. On the other hand, the number of all types of functional groups is considerably higher for Haplic Luvisol, which arises from higher amount of organic carbon.

The $\mathrm{pH}$ value of biochar is alkaline probably due to high amount of alkaline cations (Yuan et al. 2011). The density and ash content of biochar are lower and, simultaneously, the surface area is much more developed in comparison with soils. These features may be very beneficial in the improvement of soil structure (better aeration, higher surface accessible to sorption processes). The content of $C_{\text {tot }}$ and $C_{\text {org }}$ in biochar is substantially higher mainly due to presence of carbonates and incomplete pyrolysis of organic substance. The material is also characterized by large number of functional groups, both acidic and phenolic. This fact indicates great abilities to the chemical interactions including metal bindings.

Generally, the five chemically different mechanisms have been recognized as possible for the explanation of sorption of heavy metals on biochar ( $\mathrm{Li}$ et al. 2017) : surface adsorption via coordination to $\pi$ electrons $(\mathrm{C}=\mathrm{C})$, precipitation of $\mathrm{Cu}$ as insoluble compounds, metal ionic exchange with cations, surface complexation by functional groups and electrostatic interactions ( $\mathrm{Lu}$ et al. 2012; Cao et al. 2011; Chen et al. 2011; Tong et al. 2011). The role of each mechanism depends on the type of heavy metal, environmental conditions and adsorbent properties. It has been also proved that, due to the structure of biochar, sorption of heavy metals can occur as a result of the partitioning mechanism on the noncarbonized fraction and surface adsorption on the carbonized fraction. In case of the $\mathrm{Cu}$ removal, Tong et al. (2011) have reported that sorption of $\mathrm{Cu}$ on the biochar may occur on the way of electrostatic attraction between the surface sorbent and the sorbate and by the complexation of $\mathrm{Cu}$ with carboxyl and hydroxyl groups. These complexes appear to be in the forms of inner-sphere compounds formation with free and complexed - $\mathrm{COOH}$ and -OH (Kołodyńska et al. 2012). Some kinds of oxygen containing functional groups may be responsible for increased hydrophobicity and affinity for metal ions as well as reduction of the competitive adsorption processes with participation of water molecules (Kołodyńska et al. 2012; Li et al. 2017). Cu can be also adsorbed by co-precipitation or surface precipitation. Heavy metals can form precipitates with hydroxyl, phosphate and carbonate anions particularly in the neutral and alkaline conditions and such metal species may spontaneously cover biochar surface (Tong et al. 2011).

The biochar contains high $\mathrm{Cu}$ amount, but it does not have a major impact on adsorption process. Heavy metals are stable in the structure of biochar, and their leaching is very low (Hossain et al. 2011; Jin et al. 2014; Agrafiotia et al. 2013; Lu et al. 2013; Hernande et al. 2011; He et al. 2010; Hwang et al. 2007; Kistler et al. 1987).

\section{Kinetics of $\mathrm{Cu}$ adsorption on the soils in the absence and presence of biochar}

Figure 1a, b presents kinetic adsorption isotherms evaluated for samples of two investigated soils modified with different amounts of biochar $(0.01$ and $0.1 \%)$, at constant concentration of $\mathrm{Cu}(10 \mathrm{mg} / \mathrm{l}), c_{0}$, and at $\mathrm{pH}=6.5$.

The isotherms of kinetic were analyzed using several kinetic equations reported in the review of Ho (2006b). Among all those equations, the equation of Ritchie, Eq. (5), was the superior. Indeed, this equation fits experimental data quite well and the squared correlation coefficient has been higher than 0.999 for all the samples (Table 3). The rate constant, $\alpha$, was evaluated as $\alpha=a / b$. At a fixed initial concentration of $\mathrm{Cu}$ and for each soil type, an increase in the content of biochar leads to faster sorption of $\mathrm{Cu}$, which is also noticeable as more steep shape of isotherms in case of higher dose of biochar. This can indicate that addition of biochar played a role of source of adsorption sites for metal ions (Beesley et al. 2014). Chemical analysis of biochar shows that this material contains reasonable amount of organic carbon and high value of negative surface charge which suggests high content of organic functional groups responsible for $\mathrm{Cu}$ binding (Uchimiya et al. 2011b).

Adsorption was stronger for Haplic Luvisol than for Haplic Podzol, which besides the effect of biochar could result from higher amount of silt and clay fractions in the loess soil. Mechanism of metal binding by soil components is not well recognized. However, some publications reported that despite unquestionable function of organic matter, clay minerals may also take part in d-electron metals binding on the way of complex mechanisms (Parker and Rae 2013). Clay minerals (such as kaolinite, montmorillonite and illite) stand out because of their high potential to heavy metals 

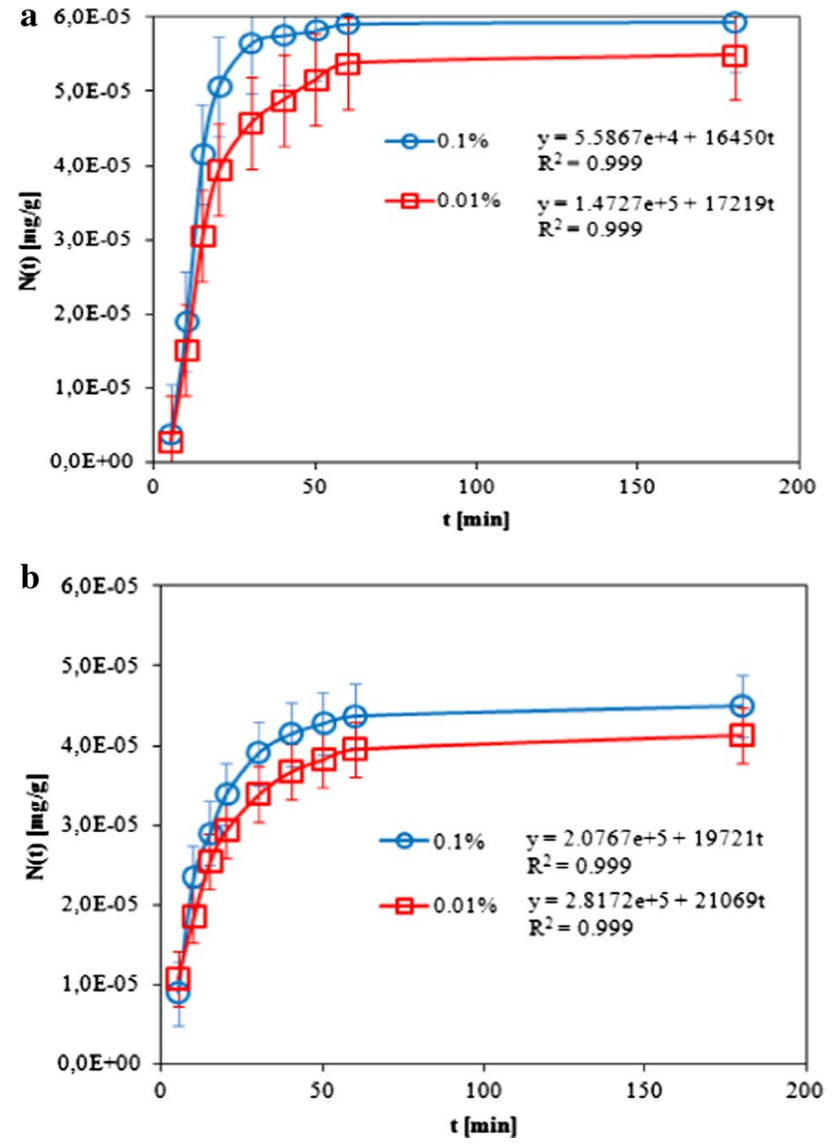

Fig. 1 Experimental kinetic isotherms of $\mathrm{Cu}$ on silty Haplic Luvisol (a) and on sandy Haplic Podzol (b), modified with biochar

binding and high sorption capacity. They have protruding $-\mathrm{OH}$ groups, which are points of ion exchange (Nessner Kavamura and Esposito 2010). The negative charge is neutralized by positive ions (heavy metals) from the aqueous solution in contact. However, sandy soils, distinguished by a low sorption capacity and acidity, weakly absorb heavy metals, which lead to their movement to groundwater and surface water (Fijalkowski et al. 2012). In consequence, granulometric composition of the soil materials seems to be an important factor in $\mathrm{Cu}$ adsorption. In the vast majority of cases, the sorption "is completed" after $1 \mathrm{~h}$ and the isotherms of kinetic attain plateaus, corresponding to relevant capacities of adsorption. It can thus conclude that in all the cases the time of $3 \mathrm{~h}$ is sufficient for performing adsorption equilibrium measurements. Of course, the capacity of a sorbent, $N_{\infty}$, increased as the initial concentration of $\mathrm{Cu}$ in solution increased.

As it was already mentioned, the Elovich equation (Cheung et al. 2000) was also used to model experimental data, but the quality of the fits was definitely worse than of the Ritchie equation (the relevant data have been omitted). The Elovich equation was often applied satisfactorily to some chemisorption data and was found to cover a large range of slow adsorption cases (Low 1960; Taylor et al. 1995). This equation is often valid for systems in which the adsorbing surface is heterogeneous. Indeed, the Elovich kinetic equation is closely related to the Jovanovic equilibrium isotherm and the latter equation is known as describing adsorption on heterogeneous surfaces (Jaroniec and Madey 1988; Jaroniec and Piotrowska 1986). Soil samples modified with biochar seem to fulfill the criterion of the high surface heterogeneity; however, rapid process of $\mathrm{Cu}$ adsorption could be the reason of worse working of the Elovich equation.

\section{Amount of $\mathrm{Cu}$ adsorption on the soils as a function of biochar dose and $\mathrm{pH}$ value}

Before measurements of adsorption, the additional experiments were carried out, which were aimed at a more detailed characterization of soil modified by biochar. Namely, the specific surface area $(S)$ of the samples was determined. For a more detailed assessment of the relationship between $S$ values and amount of biochar, the dose was extended to $10 \%$. The results are presented in Fig. 2.

The specific surface area of the non-modified silty Haplic Luvisol is almost three times higher than the sandy Haplic Podzol. An increase in the content of biochars leads to an increase in the $S$ values, and the linear dependences of $S$ versus $p$, the percent of biochar, run almost perfectly inparallel. The correlation coefficients of the evaluated regression lines were very close to 1 . The slopes of the regression lines are almost identical, i.e., addition of biochar to both soils leads to identical changes in their specific surface area. This suggests that the interactions of soil with biochar are
Table 3 Examples of the linear form of Ritchie's kinetic equation (Eq. 3) for selected samples

\begin{tabular}{lllcl}
\hline Soil & $\begin{array}{l}\text { Concentration of } \\
\text { biochar (\%) }\end{array}$ & Equation (3) & $\begin{array}{l}\text { The rate constant, } \\
\alpha(1 / \mathrm{min})\end{array}$ & $\begin{array}{l}\text { Correlation } \\
\text { coefficient }\end{array}$ \\
\hline Haplic Luvisol & 0.01 & $y=1.4727 \mathrm{e}+5+17219 t$ & 8.553 & 0.999 \\
& 0.1 & $y=5.5867 \mathrm{e}+4+16450 t$ & 3.396 & 0.999 \\
Haplic Podzol & 0.01 & $y=2.8172 \mathrm{e}+5+21069 t$ & 13.371 & 0.999 \\
& 0.1 & $y=2.0767 \mathrm{e}+5+19721 t$ & 10.530 & 0.999 \\
\hline
\end{tabular}

The amount of adsorbed ions is expressed in $\mathrm{mg} / \mathrm{g}$, and the time in $\mathrm{min}$ 


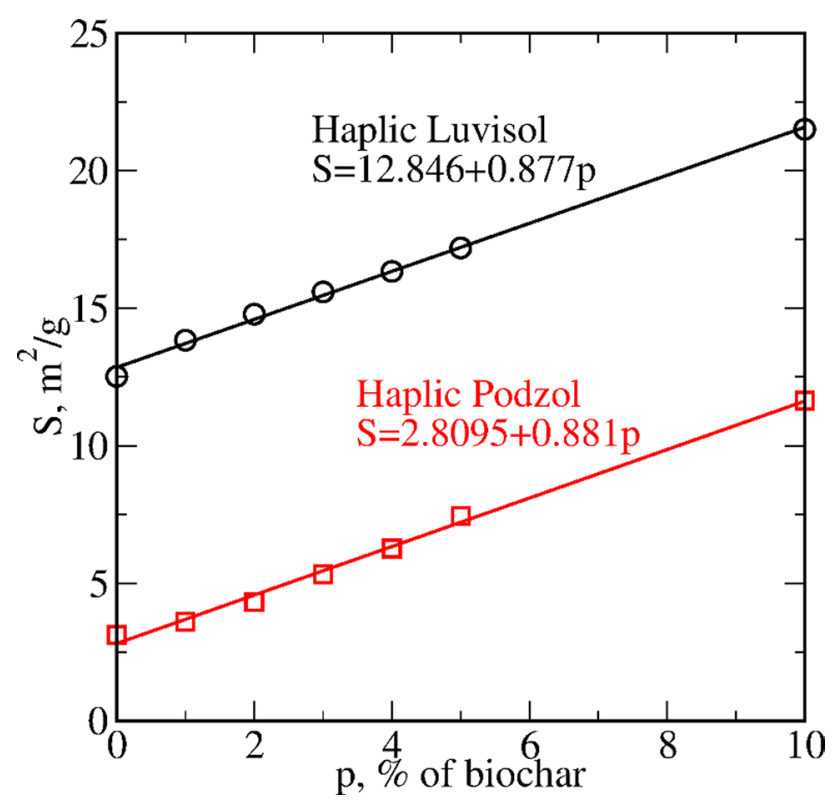

Fig. 2 The dependence of the specific surface area $S$ of the silty Haplic Luvisol and of the sandy Haplic Podzol on the percentage of added biochar. Points denote experimental data, and lines have been obtained from linear regression. The corresponding approximating equations are given in the figure

very weak, at least in the case of measurements of adsorption from gaseous phase. Similar linear dependence was also confirmed in system of sandy soil mixed with another natural source of organic matter (peats) by Sokołowski et al. (2009). Authors have described that the linear correlations exist if the samples are produced by mixing components containing a small amount of organic material with the samples rich in organic carbon (e.g., compost or peat). If the interactions between the mixed components are weak, then the plot can be modeled by a straight line. However, in the case of more pronounced interactions, the dependence on the amount of organic matter becomes more complex. Larger specific surface area of Haplic Luvisol studied in this paper can result both from higher amount of organic carbon as well as clay and silt materials in comparison with Haplic Podzol (Table 1). Therefore, we can expect that non-modified as well as modified with biochar samples of sandy soil exhibit lower sorption properties than the solid samples of silty soil.

Figures 3 and 4 present experimental adsorption isotherms of $\mathrm{Cu}$ on non-modified and modified soils with three different doses of biochars at three values of $\mathrm{pH}=3,5$ and 6.5. General observations are as follows. The addition of biochar increases adsorption in the whole range of investigated concentrations of $\mathrm{Cu}$, i.e., the isotherms for different doses of biochar do not intersect. However, an increase in the adsorption is not proportional to the dose of biochar. This may result from complex and non-stoichiometric mechanism of adsorption. Adsorption of $\mathrm{Cu}$ on biochar mainly occurred
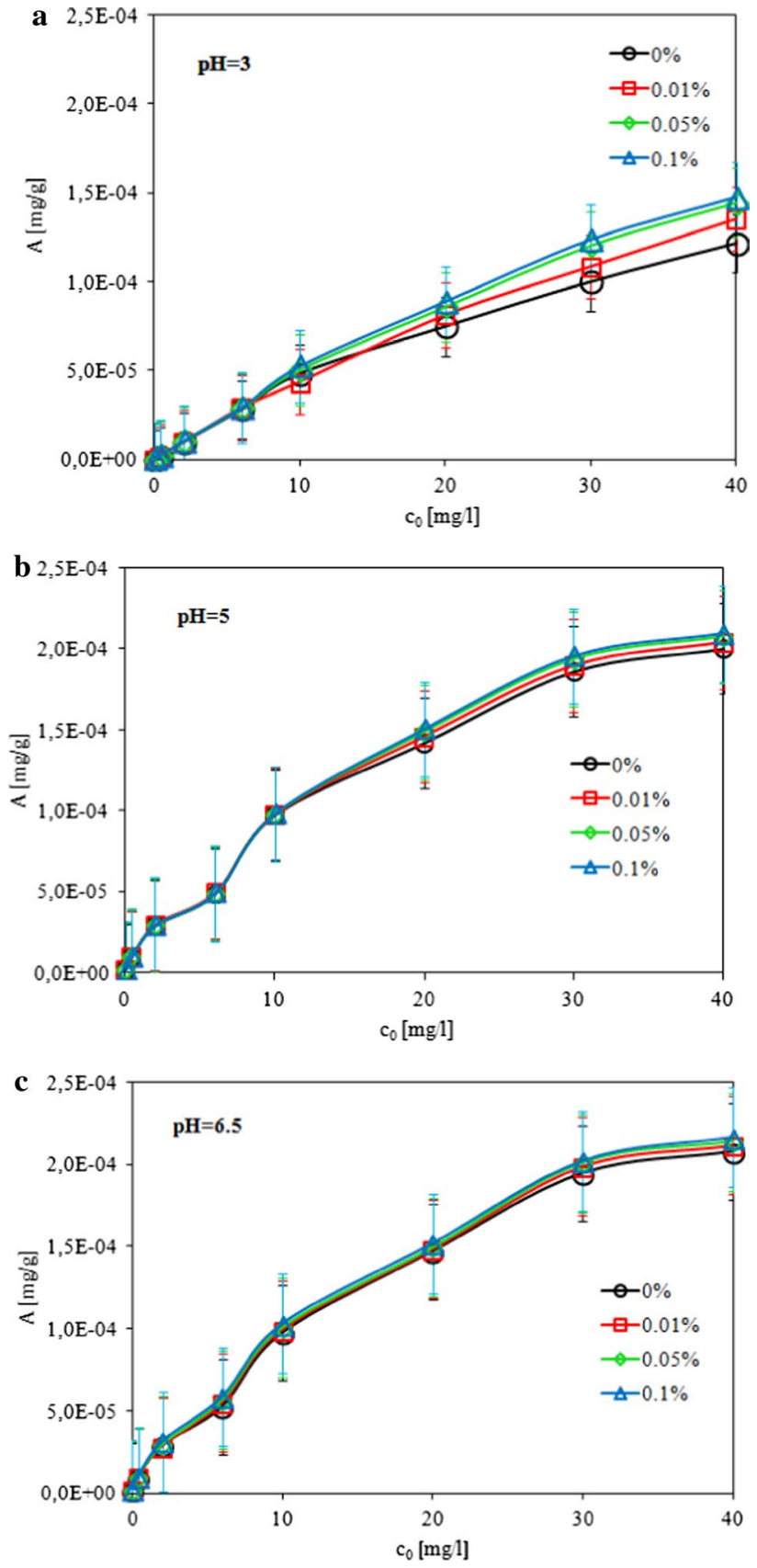

Fig. 3 Experimental adsorption isotherm of $\mathrm{Cu}$ on Haplic Luvisol modified with different doses of biochar, given in the figure. Consecutive $\mathbf{a}-\mathbf{c}$ are for $\mathrm{pH}=3,5$ and 6.5 , respectively

through binding with the functional groups (carboxylic and phenolic). $\mathrm{Cu}$ was adsorbed by complexion with the functional groups on biochar. Meanwhile, surface-loaded biochar could introduce many additional functional groups, through which soil could bind to $\mathrm{Cu}$, thus increasing the amount of $\mathrm{Cu}$ adsorption. The amount of $\mathrm{Cu}$ adsorption increased with the increase in doses of biochar. According to Lu et al. (2012), possible interactions of biochar-soil with metal can 

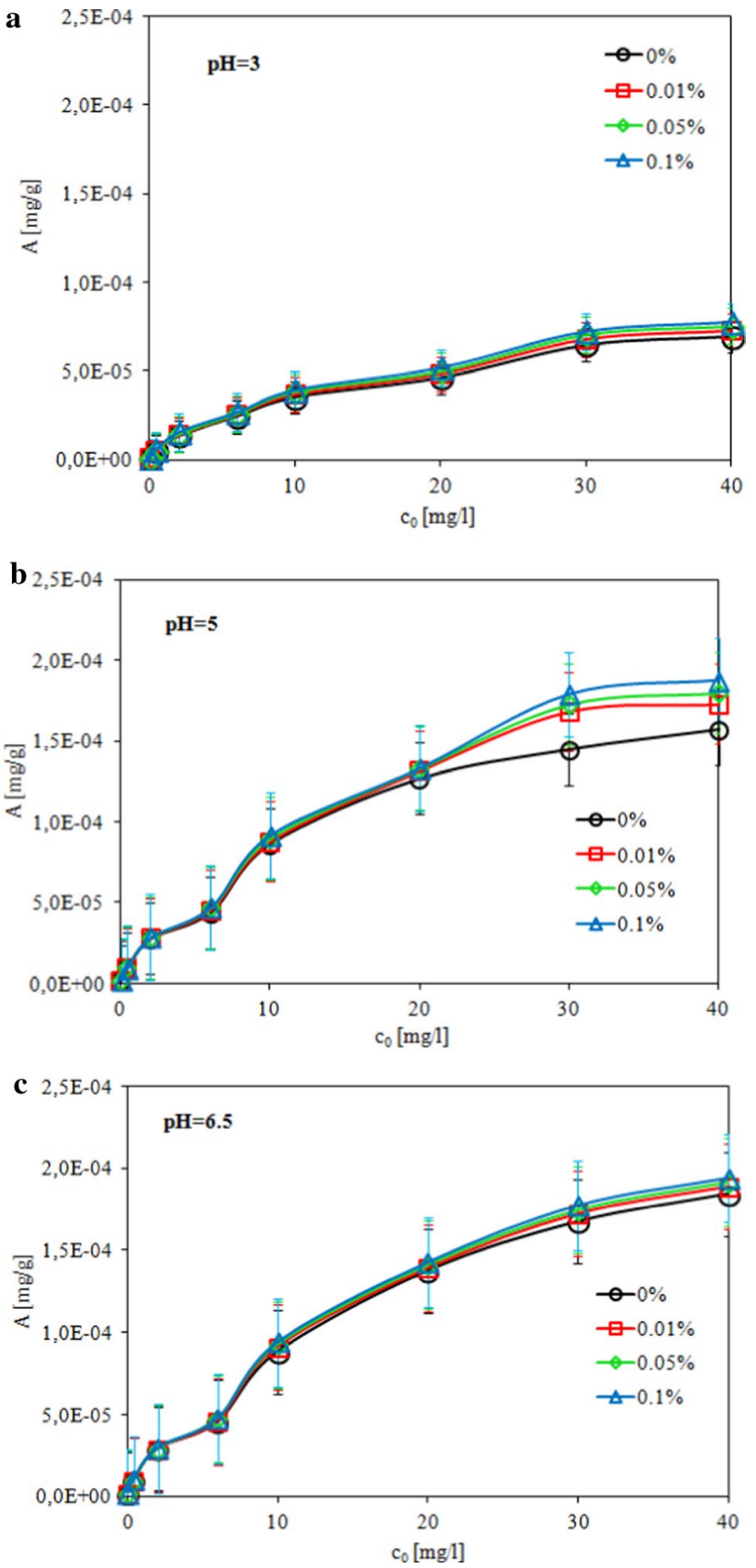

Fig. 4 Experimental adsorption isotherm of $\mathrm{Cu}$ on Haplic Podzol modified with different doses of biochar, given in the figure. Consecutive $\mathbf{a}-\mathbf{c}$ are for $\mathrm{pH}=3,5$ and 6.5 , respectively

include also electrostatic outer-sphere complexation due to metal exchange $\mathrm{K}$ and $\mathrm{Na}$ ions, co-precipitation and innersphere complexation of metals with organic matter and mineral or oxides of the soil, surface complexation with active carboxyl and hydroxyl functional groups and others.

An increase in $\mathrm{pH}$ leads to higher adsorption, and this effect is observed for both soils. $\mathrm{Cu}$ are the most strongly adsorbed at $\mathrm{pH} 6.5$ due to the fact that increase in $\mathrm{pH}$ leads to dissociation of functional groups of organic particles. Carboxylic and phenolic groups generate negative charge and as a consequence attraction of positively charged metal cations becomes easier (Boguta et al. 2016b). Simultaneously, $\mathrm{pH} 6.5$ is a point when $\mathrm{Cu}$ is still mainly present as $\mathrm{Cu}$; therefore, it can be concluded that prevalent part of $\mathrm{Cu}$ is removed from the solution on the way of binding by functional groups. However, it should be noted that trace concentrations of hydrolyzed $\mathrm{Cu}$ forms can also begin to appear in pH close to 7 and above (Alloway 1995).

Finally, adsorption on silty Haplic Luvisol samples is remarkably higher than the adsorption on sandy Haplic Podzol. Of course, this is due to different nature of both soils. The sample of non-modified silty Haplic Luvisol contains more organic carbon than the sample of the sandy Haplic Podzol. Haplic Luvisol shows also about two times higher number of functional groups, five time higher surface area and about seven times higher content of clay and silt fractions as compared to Haplic Podzol (Tables 1, 2).

It is also known that $\mathrm{Cu}$ can form not only different complexes with surface groups of organic matter (mainly with humins and humic acids connected with mineral part of soil), but they can also form complexes with a part of organic matter that has dissolved in the bulk solvent (low molecular organic compounds, dissolved humic and fulvic acids). The dissolved organic carbon concentration passage of organic matter from solid to liquid phase depends on $\mathrm{pH}$ of solution, but also on the concentration of $\mathrm{Cu}$ (Chotzen et al. 2017). Moreover, the active groups of biochars responsible for binding of $\mathrm{Cu}$ can interact and form chemical bonds with mineral components of soils. All the above processes compete each other, and this can also explain why the sorption ability of modified soils is not proportional to the amount of biochar (Figs. 3, 4). In particular, a tendency to form metal-organic matter complexes increases with increase in $\mathrm{pH}$ due to dissociation of functional groups. However, $\mathrm{pH}$ increase leads also to dissolve some amount of organic substance, and this fraction can form soluble complexes with $\mathrm{Cu}$ (Boguta et al. 2016a). It can be additionally promoted, because according to Beesley et al. (2010) and Park et al. (2011) biochar can enhance trace elements solubility (including $\mathrm{Cu}$ ) when dissolved organic $\mathrm{C}$ is released. Dissolved organic $\mathrm{C}$ can block the pores of biochars preventing $\mathrm{Cu}$ sorption (Cao et al. 2011). The formation of soluble complexes causes the true bulk concentration of $\mathrm{Cu}$ that remain in equilibrium with adsorbed phase to be, in fact, lower. Moreover, at higher $\mathrm{pH}(\mathrm{pH}=6.5)$ the $\mathrm{Cu}$ can precipitate in trace amount (Alloway 1995) and form different hydroxides on the adsorbent surface. According to Albrecht et al. (2011) and Boguta and Sokołowska (2013) at low concentrations of $\mathrm{Cu}$, the $\mathrm{Cu}$ ion, $\mathrm{Cu}^{2+}$, is the dominant species at low values of $\mathrm{pH}$. At higher $\mathrm{pH}$ values, $\mathrm{Cu}$ hydroxide, $\mathrm{Cu}(\mathrm{OH})_{2}^{2+}$, is the dominant species up to $\mathrm{pH} 12.3$ where the $\mathrm{Cu}$ ion $\mathrm{Cu}(\mathrm{OH})_{3}$-forms. At 
higher concentrations of $\mathrm{Cu}$, solid $\mathrm{Cu}(\mathrm{OH})_{2}$ is formed and precipitates out of solution at $\mathrm{Cu}$ concentrations above the solubility product of $\mathrm{Cu}$ hydroxide. It is important to note that the domain of stability of solid $\mathrm{Cu}(\mathrm{OH})_{2}$ is expanding to lower and higher values of $\mathrm{pH}$ with the increase in the concentration of $\mathrm{Cu}$. A small but significant amount of an important $\mathrm{Cu}$ complex $\mathrm{Cu}(\mathrm{OH})^{+}$is formed at low $\mathrm{pH}(3-7)$. Consequently, any theoretical description that concentrates only on the reactions connected with passage of ions from bulk solution to surface phase and neglects all remaining processes must be approximate.

In order to get insight, how the organic matter changes its status and passes from solid to solute phase, we have determined the content of the total organic carbon (TOC) in the solutions after performing adsorption experiments. Examples of the obtained curves are displayed in Fig. 5.

In general, the process of organic matter leaching is less pronounced for Haplic Luvisol than for Haplic Podzol despite the higher content of organic matter in the first one. This difference arises from higher content of silt and clay mineral fractions in Haplic Luvisol. Organic compounds such as humins, humic and fulvic acids form stable chemical bindings with clay minerals which can hamper its releasing to solution. Previous studies revealed that some kinds of clay minerals can be used even as efficient adsorbents for removal of organic pollutants (including humic acids) from waters (Chotzen et al. 2017; Szabó et al. 2016). Increase in pH value results in the increase in the concentration of organic carbon in the liquid phase. It is due to dissociation of consecutive functional groups with elevation of $\mathrm{pH}$ (Sokołowska et al. 2011). The concentration of biochar shows slight positive effect on releasing organic carbon at low dose of biochar (in most cases at $p=0.01 \%$ ). Higher doses of biochar do not change concentrations of organic carbon unambiguously. This can suggest that source of organic carbon in the solution is organic matter contained in soils, whereas low concentrations of biochar can modify solubility of "native" organic matter of soil by forming chemical bonds with mineral components of soils. Concentration of $\mathrm{Cu}$ show ambiguous influence. Slight decrease in organic carbon concentration in solution under increase in concentration of $\mathrm{Cu}$ takes place in case of Haplic Luvisol. It could be in accordance with results obtained by Chotzen et al. (2017) that sorption of humic acid to clay mineral (kaolinite) increased in the presence of $\mathrm{Cu}$.

Experimental adsorption isotherms were modeled in terms of the Langmuir-Freundlich equation, Eq. (8) with $n=1$. This equation was found to describe several adsorption data quite well, especially those obtained at $\mathrm{pH}=3$. At $\mathrm{pH}=5$, a reasonably good description was found only in the case of Haplic Luvisol samples. At $\mathrm{pH}=6.5$, however, the Langmuir-Freundlich equation failed completely and our trials to model experimental data with the Langmuir-Freundlich equation led to unphysical (negative) values of $K$. Table 4 collets the results. For the reported data, the squared correlation coefficients were higher than 0.96 .

The physical meaning of the parameters of the Langmuir-Freundlich equation, resulting form its theoretical derivation, is as follows. The parameter $A_{m}$ corresponds to the amount of the surface sites available to the adsorbing ions, the parameter $K$ describes affinity of $\mathrm{Cu}$ to the surface, and finally the parameter $m$ is related to energetic heterogeneity of the adsorbing surfaces: Larger surface heterogeneity is reflected by lower values of $m$. An increase

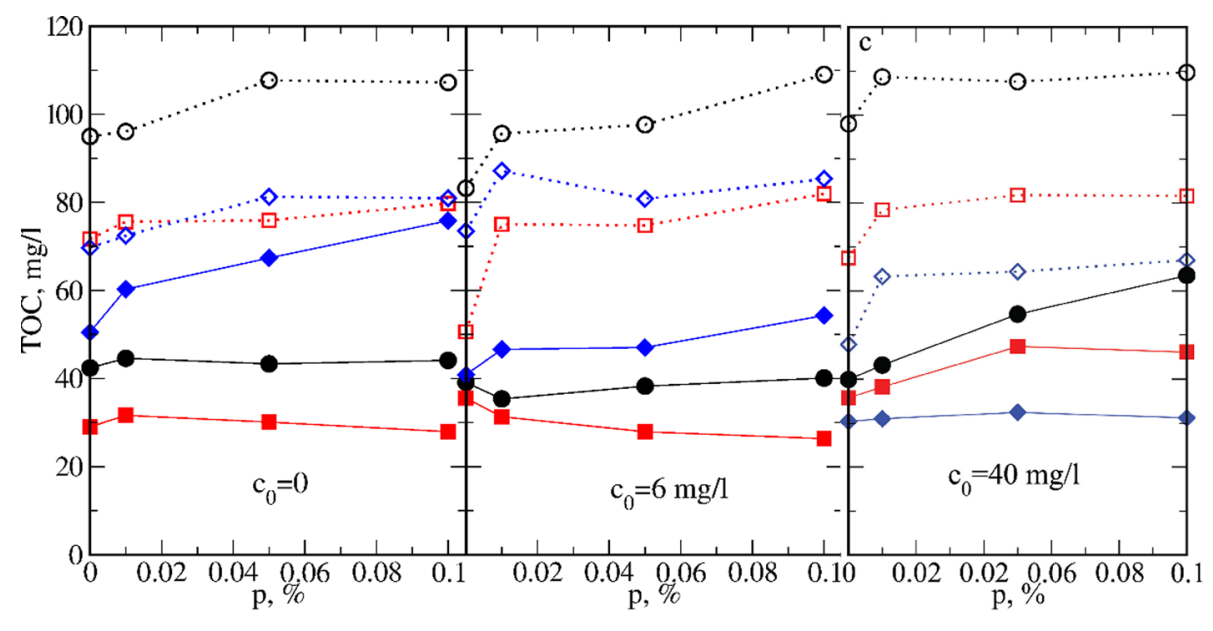

Fig. 5 Examples of the dependence of the content of the total organic carbon (TOC) in the solution after performing adsorption experiments versus the amount of the biochars, $p$. Black circles denote the results at $\mathrm{pH}=6.5$, red squares-at $\mathrm{pH}=5$ and blue diamond's-at $\mathrm{pH}=3$. Filled symbols have been evaluated for samples of Haplic
Luvisol, while empty symbols for the samples of Haplic Podzol. Left panel has been obtained for the solutions containing no $\mathrm{Cu}$, whereas next panels for the solutions with the initial $\mathrm{Cu}$ concentration equal to $c_{0}=6 \mathrm{mg} / \mathrm{l}$ and $c_{0}=40 \mathrm{mg} / \mathrm{l}$ 
Table 4 Constants Langmuir-Freundlich equation, Eq. (6) with $n=1$, for soils modified with different amounts of biochar

\begin{tabular}{llllll}
\hline Soil & $\mathrm{pH}$ & $\begin{array}{l}\text { Concentration } \\
\text { of biochar } p \\
(\%)\end{array}$ & $\begin{array}{l}\text { Langmuir-Freundlich fitting } \\
\text { parameters }\end{array}$ \\
\cline { 4 - 6 } & & $K_{\mathrm{LF}}(1 / \mathrm{mg})$ & $A_{m}(\mathrm{mg} / \mathrm{g})$ & $m$ \\
\hline Haplic Luvisol & 3 & 0 & 1.727 & $1.72 \mathrm{E}-4$ & 0.824 \\
& & 0.01 & 1.747 & $1.999 \mathrm{E}-4$ & 0.859 \\
& & 0.05 & 2.834 & $1.89 \mathrm{E}-4$ & 0.925 \\
& & 0.1 & 3.681 & $1.993 \mathrm{E}-4$ & 0.972 \\
Haplic Luvisol & 5 & 0 & 2.403 & $9.327 \mathrm{E}-4$ & 0.97 \\
& & 0.01 & 1.780 & $1.369 \mathrm{E}-3$ & 0.99 \\
& & 0.05 & 13.279 & $3.449 \mathrm{E}-4$ & 1.3 \\
Haplic Podzol & 3 & 0.1 & 3.682 & $8.910 \mathrm{E}-4$ & 1.15 \\
& 0.01 & 0.189 & $1.764 \mathrm{E}-4$ & 0.92 \\
& 0.05 & 0.153 & $2.083 \mathrm{E}-4$ & 0.901 \\
& 0.1 & 1.426 & $7.455 \mathrm{E}-5$ & 0.895 \\
& & 0.215 & $1.864 \mathrm{E}-4$ & 0.890 \\
\hline
\end{tabular}

in the content of biochar in the samples of Haplic Luvisol leads to an increase in $m$, i.e., diminishes surface heterogeneity, whereas in the case of Haplic Podzol the parameter $m$ decreases indicating heterogeneity improving. The influence of $\mathrm{pH}$ on the parameters from Table 4 is mainly related to the fact that at lower $\mathrm{pH}$ protonation of functional groups occurs (blocking these groups) as a result of which there is a decrease in the number of active sites for ion adsorption, which is also the parameter $K$, parameter $m$, which is related to the surface energy heterogeneity (Kobya et al. 2005). However, at $\mathrm{pH}=5$ and for Haplic Luvisol the values of $m$ are slightly lower than 1 for small amount of biochar and somewhat higher than 1 for larger content of biochar. This may suggest more complex mechanism of accumulation of surface complexes binding $\mathrm{Cu}$ than that assumed by simple Langmuir-Freundlich model (Marczewski and Szymula 2002). However, an increase in the $\mathrm{Cu}$ concentration causes the increase in the concentration of $\mathrm{Cu}$ (II) adsorbed on the adsorbent mass unit, which is the increase in the concentration of the active sites in the solution. This is confirmed by publications (Pellera et al. 2012; Aydin and Bulut 2008; El-Ashtoukhy et al. 2008). The variation of the values of $K_{\mathrm{LF}}$ does not exhibit any systematic trend with the dose of biochar with the expectation of Haplic Luvisol causes at $\mathrm{pH}$ 3 where the value of the parameter $K_{\mathrm{LF}}$ increases, indicating higher adsorbing affinity of $\mathrm{Cu}$ of modified soils. It also should be noted that $K$-values are generally higher at pH 5 than at pH 3 and lower for Haplic Podzol as compared to Haplic Luvisol (effect of the higher organic carbon as well as content of clay and silt fractions in Haplic Luvisol discussed above in this paper).

Of course, each set of experimental data can be quite well modeled using generalized Dubinin-Radushkevich equation, Eq. (10). It recalls that in contrast to Langmuir-Freundlich isotherm, the Dubinin-Radushkevich equation corresponds to a multi-maxima distribution of adsorption sites. An example of the obtained fits collects is given in Table 5. There are data which were not well modeled by Langmuir-Freundlich model.

However, one can ask the question whether this is not simply the result of "flexibility" of mathematical form of Eq. (10) and cannot provide any important information about physics of the adsorption process. Almost all theoretical models of adsorption employed in a vast majority of studies are based on the assumption that the only allowed changes in the adsorbent body are those directly connected with adsorption process, i.e., the binding of adsorbing molecules to the active sites of the adsorbent. Other adsorbent changes (e.g.,
Table 5 Analytical forms of the generalized DubininRadushkevich Eq. (8) evaluated for adsorption data on soils modified with different amounts of biochar

\begin{tabular}{llll}
\hline Soil & $\mathrm{pH}$ & $\begin{array}{l}\text { Concentration of } \\
\text { biochar } p(\%)\end{array}$ & Generalized equation Dubinin-Radushkevich \\
\hline Haplic Luvisol & \multirow{2}{*}{6.5} & $p=0$ & $y=7.1017+13.822 x+3.9934 x^{2}+0.40123 x^{3}$ \\
& & $p=0.01$ & $y=18.534+22.567 x+6.1795 x^{2}+0.57824 x^{3}$ \\
& & $y=0.05$ & $y=16.156+19.872 x+5.3042 x^{2}+0.49034 x^{3}$ \\
& & $p=0.10$ & $y=11.164+15.724 x+4.2128 x^{2}+0.39617 x^{3}$ \\
Haplic Podzol & 5 & $p=0$ & $y=-8.1809+1.5736 x+0.52425 x^{2}+0.077963 x^{3}$ \\
& & $p=0.01$ & $y=-9.7281-3.5429 x-3.6649 x^{2}-1.1649 x^{3}-0.12049 x^{4}$ \\
& & $p=0.05$ & $y=-9.6541-3.243 x-3.2837 x^{2}-1.0183 x^{3}-0.10367 x^{4}$ \\
& & $p=0.10$ & $y=-9.6456-3.252 x-3.2117 x^{2}-0.9807 x^{3}-0.098927 x^{4}$ \\
& & $p=0$ & $y=-6.4834+2.1178 x+0.51242 x^{2}+0.060402 x^{3}$ \\
& & $p=0.01$ & $y=-5.58+2.8654 x+0.71648 x^{2}+0.075072 x^{3}$ \\
& & $p=0.05$ & $y=-5.5535+2.7566 x+0.66778 x^{2}+0.068777 x^{3}$ \\
\hline
\end{tabular}

$y=\ln A, x=\ln (c)$, the values of $A$ and $c$ are in $\mathrm{mg} / \mathrm{g}$ and in $\mathrm{mg} / \mathrm{l}$, respectively. The value of the parameter $c_{m}$ was $1 \mathrm{mg} / \mathrm{l}$ 
its dissolution) are excluded. However, the results presented in Fig. 5 indicate that the adsorbents studied by us change during adsorption process and that those changes depend on the concentration of the adsorbing ions. Therefore, even in the cases when a given equation is found as well modeling experimental data, the interpretation of physical meaning of its parameters requires special care and in several cases the employed equation should be treated as "mathematically appropriate function" to describe the data rather than confirmation of a given mechanism of adsorption process.

\section{Biochar efficiency in the Cu removal}

Based on the result of $\mathrm{Cu}$ adsorption amount measurements, performed under various $\mathrm{pH}$ conditions, in the presence of different doses of biochar, the biochar efficiency was calculated. Silty Haplic Luvisol non-containing biochar adsorbed $62 \%$ of $\mathrm{Cu}$ present in the sample at $\mathrm{pH} 3,97 \%$ at $\mathrm{pH} 5$ and $98 \%$ at $\mathrm{pH} 6.5$. When the sample contained $0.01 \%$ of biochar, the $72.5 \%(\mathrm{pH} 3), 98 \%(\mathrm{pH} 5)$ and $98 \%(\mathrm{pH} 6.5)$ of $\mathrm{Cu}$ was adsorbed. In turn, in the biochar presence in the amount of $0.1 \%$, the efficiency of adsorption $\mathrm{Cu}$ was equal to $74 \%$ (pH 3), 98\% (pH 5) and 99\% (pH 6.5). The above results showed that the biochar efficiency in the silty Haplic Luvisol is the largest at $\mathrm{pH} 3$, with its content equal to $0.1 \%$. Under these conditions, the addition of biochar contributes to the increase in $\mathrm{Cu}$ sorption efficiency by $10.5 \%$ (compared to the soil non-containing biochar). The biochar efficiency at pH 5 and 6.5 was not as clear as at $\mathrm{pH} 3$, and it equals $1 \%$. It was connected with the fact that under these conditions the soil without biochar is a very good sorbent for $\mathrm{Cu}$ and binds almost all metal cations present in the probe. It must be also emphasized that the $\mathrm{Cu}$ adsorption on the Haplic Luvisol was faster when the soil contained higher amount of biochar. About $95 \%$ of $\mathrm{Cu}$ present in the sample was adsorbed after 30 min by Haplic Luvisol containing $0.1 \%$ of biochar. The same percentage of initial $\mathrm{Cu}$ concentration was bound by this soil containing $0.01 \%$ of biochar after $50 \mathrm{~min}$.

The results obtained for sandy Haplic Podzol were different. The soil without biochar adsorbed 32\% (pH 3), 64.5\% (pH 5) and 96\% (pH 6.5) of $\mathrm{Cu}$ present in the sample. The biochar content of $0.01 \%$ affected the amount of adsorbed $\mathrm{Cu}$ that in this case was equal to $35 \%(\mathrm{pH} 3), 85.5 \%(\mathrm{pH} 5)$ and $96 \%$ (pH 6.5). In turn, $0.1 \%$ biochar addition made the $\mathrm{Cu}$ sorption efficiency equal to $36 \%(\mathrm{pH} 3), 88 \%(\mathrm{pH} 5)$ and $96 \%$ (pH 6.5). This means that biochar increased the $\mathrm{Cu}$ adsorption on the Haplic Podzol at pH 3 and 5; however, the most considerable changes were observed at $\mathrm{pH} 5$ (increase in adsorption by 23.5\%). At pH 6.5, the effect of biochar on the $\mathrm{Cu}$ adsorption was insignificant, because under these conditions almost all $\mathrm{Cu}$ is removed from the solution, even without addition of biochar.
Biochar as only adsorbent has various efficiencies. Chen et al. (2011) showed that biochar from corn straw (produced at $600{ }^{\circ} \mathrm{C}$ ) and wood biochar (produced at $450{ }^{\circ} \mathrm{C}$ ) have high heavy metal sorption efficiency. The removal of $\mathrm{Cu}$ was $56.7 \%$ for wood biochar and $98.3 \%$ for biochar from corn straw. On the other hand, Komkiene and Baltrenaite (2015) proved that heavy metal ions removal efficiency was about $35-37 \%$ on silver birch biochar. The observed differences in the biochar efficiency are associated with various kinds of biomass and temperature of pyrolysis.

The obtained results were compared with the biochar efficiencies for $\mathrm{Cu}$ adsorption reported by other scientists. Karami et al. (2011) showed that the addition of biochar (from the oak) in the amount of $20 \%(v / v)$ to the soil reduces the $\mathrm{Cu}$ sorption by about $69 \%$. On the other hand, $\mathrm{Xu}$ and Zhao (2013) proved that biochar from straws of canola and peanut increased the capacity of $\mathrm{Cu}$ sorption of three soils (Oxisol derived from basalt, Utisol derived from granite and Utisol from Quaternary red earth) by about $54.2 \%$ and $102.1 \%$, when 3 and $5 \%$ of biochar was added. The biochar from rice reduce $\mathrm{Cu}$ in ultisol derived from Quaternary red earth at the same doses (Jiang et al. 2012). Considering these results, it should be supposed that above variation in results may result from different biomass and soils, and thus, the impact of biochar should be assessed independently for individual materials.

\section{Conclusion}

In these studies, the important topic of sorption of heavy metals, such as $\mathrm{Cu}$ by biochar added to soils, was discussed. The comprehensive approach for the research problem taking into account different soils and doses of biochar as well as wide range of $\mathrm{pHs}$ allowed to receive valuable information on adsorption properties of biochar in soil environment. The obtained results have revealed that woody biochar obtained at $650{ }^{\circ} \mathrm{C}$ can be an effective material for the immobilization of the $\mathrm{Cu}$ contaminant in both sandy and loess Haplic soils at acidic pHs. The addition of biochar contributed to the increase in specific surface area in the examined soils. The experiments also proved that the acidification of the soils did not deteriorate the sorption properties of biochar; however, the removal of $\mathrm{Cu}$ was not additionally enhanced by the biochar at pH 6.5 probably due to the occurrence of the hydrolysis process of $\mathrm{Cu}$ both in the presence and without of biochar addition. The data of adsorption were correlated with kinetic equation of Ritchie, adsorption isotherms of Langmuir-Freundlich and isotherm of Dubinin-Radushkevich. Models proved to be effective in the description of the process. These findings can have significant values in predicting of the biochar adsorption properties for other 
research systems. The manuscript has implication on the management of biochar as contaminant remover and as a soil amendment.

Acknowledgements I would like to thank prof. Zofia Sokołowska and prof. Stefan Sokołowski for valuable advices.

\section{Compliance with ethical standards}

Conflict of interest The authors declare that they have no conflict of interest.

Funding Research was part conducted under the project "Water in soil-satellite monitoring and improving the retention using biochar" no. BIOSTRATEG3/345940/7/NCBR/2017 which was financed by Polish National Centre for Research and Development in the framework of "Environment, agriculture and forestry"-BIOSTRATEG strategic $\mathrm{R} \& \mathrm{D}$ programme

OpenAccess This article is distributed under the terms of the Creative Commons Attribution 4.0 International License (http://creativeco mmons.org/licenses/by/4.0/), which permits unrestricted use, distribution, and reproduction in any medium, provided you give appropriate credit to the original author(s) and the source, provide a link to the Creative Commons license, and indicate if changes were made.

\section{References}

Agrafiotia E, Bourasa G, Kalderisb D, Diamadopoulos E (2013) Biochar production by sewage sludge pyrolysis. J Anal Appl Pyrol 101:72-78

Ahmad M, Rajapaksha AU, Lim JE, Zhang M, Bolan N, Mohan D, Vithanage M, Lee SS, Ok YS (2014) Biochar as a sorbent for contaminant management in soil and water: a review. Chemosphere 99:19-33

Albrecht TWJ, Addai-Mensah J, Fornasiero D (2011) Effect of pH, concentration and temperature on copper and zinc hydroxide formation, precipitation in solution. Chemeca 2011: engineering a better world. Sydney Hilton Hotel, Australia, pp 18-21

Alburquerquel JA, Calero JM, Barrón V, Torrent J, del Campillo MC, Gallardo A, Villar R (2014) Effects of biochars produced from different feedstocks on soil properties and sunflower growth. J Plant Nutr Soil Sci 177:16-25

Alloway BJ (1995) Heavy metals in soils. Chapman \& Hall, London

Aman T, Kazi A, Sabri M, Bano Q (2008) Potato peels as solid waste for the removal of heavy metal copper(II) from waste water/industrial effluent. Colloid Surface B Biointerfaces 63:116-121

Aydin H, Bulut Y (2008) Removal of copper (II) from aqueous solution by adsorption onto low-cost adsorbents. J Environ Manage $87: 37-45$

Beesley L, Moreno-Jiménez E, Gómez-Eyles JL (2010) Effects of biochar and greenwaste compost amendments on mobility, bioavailability and toxicity of inorganic and organic contaminants in a multi-element polluted soil. Environ Pollut 158:2282-2287

Beesley L, Inneh OS, Norton GJ, Moreno-Jiménez E, Pardo T, Clemente R, Dawson JJC (2014) Assessing the influence of compost and biochar amendments on the mobility and toxicity of metals and arsenic in a naturally contaminated mine soil. Environ Pollut 186:195-202
Boehm HP (2002) Surface oxides on carbon and their analysis: a critical assessment. Carbon 40:145-149

Bogusz A, Oleszczuk P, Dobrowolski R (2015) Application of laboratory prepared and commercially available biochars to adsorption of cadmium, copper and zinc ions from water. Bioresour Technol 196:540-549

Boguta P, Sokołowska Z (2013) Influence of copper(II) ions on stability of dissolved humic acids: coagulation studies. Acta Agrophys 20:253-267

Boguta P, D'Orazio V, Sokołowska Z, Senesi N (2016a) Effects of selected chemical and physicochemical properties of humic acids from peat soils on their interaction mechanisms with copper ions at various pHs. J Geochem Explor 168:119-126

Boguta P, Pieczywek PM, Sokołowska Z (2016b) A comparative study of the application of fluorescence excitation-emission matrices combined with parallel factor analysis and nonnegative matrix factorization in the analysis of $\mathrm{Zn}$ complexation by humic acids. Sensors 16:1760

Cao X, Ma L, Liang Y, Gao B, Harris W (2011) Simultaneous immobilization of lead and atrazine in contaminated soils using dairymanure biochar. Environ Sci Technol 45:4884-4889

Chen X, Chen G, Chen L, Chen Y, Lehmann J, McBride MB, Hay AG (2011) Adsorption of copper and zinc by biochars produced from pyrolysis of hardwood and corn straw in aqueous solution. Bioresour Technol 102:8877-8884

Cheung CW, John F, Porter JF, McKay G (2000) Elovich equation and modified second-order equation for sorption of cadmium ions onto bone char. J Chem Technol Biotechnol 75:963-970

Chotzen RA, Polubesova T, Chefetz B, Mishael YG (2017) Adsorption of soil-derived humic acid by seven clay minerals: a systematic study. Clay Miner 64:628-638

Duan S, Wang Y, Liu X, Shao D, Hayat T, Alsaedi A, Li J (2017) Removal of U(VI) from aqueous solution by amino functionalized flake graphite prepared by plasma treatment. ACS Sustain Chem Eng 5:4073-4085

El-Ashtoukhy E-SZ, Amin NK, Abdelwahab O (2008) Removal of lead(II) and copper(II) from aqueous solution using pomegranate peel as a new adsorbent. Desalination 223(1-3):162-173

Fijalkowski K, Kacprzak M, Grobelak A, Placek A (2012) The influence of selected soil parameters on the mobility of heavy metals in soils. Inżynieria i Ochrona Środowiska 15(1):81-92 (in Polish)

Gupta VK, Nayak A (2012) Cadmium removal and recovery from aqueous solutions by novel adsorbents prepared from orange peel and $\mathrm{Fe}_{2} \mathrm{O}_{3}$ nanoparticles. Chem Eng J 180:81-90

Gupta VK, Carrott PJM, Carrott Ribeiro MML, Suhas TL (2009) Lowcost adsorbents: growing approach to wastewater treatment-a review. Crit Rev Environ Sci Technol 39(10):783-842

He YD, Zhai YB, Li CT, Yang F, Chen L, Fan XP, Peng WF, Fu ZM (2010) The fate of $\mathrm{Cu}, \mathrm{Zn}, \mathrm{Pb}$ and Cd during the pyrolysis of sewage sludge at different temperatures. Environ Technol 35:567-574

Hernande AB, Ferrasse JH, Chaurand P, Saveyn H, Borschneck D, Roche N (2011) Mineralogy and leachability of gasified sewage sludge solid residues. J Hazard Mater 191:219-227

Ho Y-S (2006a) Second-order kinetic model for the sorption of cadmium onto tree fern: a comparison of linear and non-linear methods. Water Res 40:119-125

Ho Y-S (2006b) Review of second-order models for adsorption systems. J Hazard Mater 36:681-689

Hoffmann K, Huculak-Mączka M, Popławski D (2012) Assessment of efficiency of humic acids extraction process using different fineness of lignite. Ecol Chem Eng A 19(9):1107-1113

Hossain MK, Strezov V, Chan KY, Ziolkowski A, Nelson PF (2011) Influence of pyrolysis temperature on production and nutrient properties of wastewater sludge biochar. J Environ Manag 92(1):223-228 
Hwang IH, Ouchi Y, Matsuto T (2007) Characteristics of leachate from pyrolysis residue of sewage sludge. Chemosphere 68:1913-1919

Jaroniec M, Bräuer P (1986) Recent progress in determination of energetic heterogeneity of solids from adsorption data. Surf Sci Rep 6:65-117

Jaroniec M, Madey R (1988) Physical adsorption on heterogeneous solids. Elsevier Science Ltd., New York

Jaroniec M, Piotrowska J (1986) The isotherm equations derived for adsorption on heterogeneous surfaces by assuming Jovanovič local behavior. Chem Pap 40:339-347

Jeppu GP, Clement TP (2012) A modified Langmuir-Freundlich isotherm model for simulating $\mathrm{pH}$-dependent adsorption effects. J Contam Hydrol 129-130:46-53

Jiang J, Xu RK, Jiang TY, Li Z (2012) Immobilization of Cu(II), Pb(II) and $\mathrm{Cd}(\mathrm{II})$ by the addition of rice straw derived biochar in a simulating polluted Ultisol. J Hazard Mater 229-230:145-150

Jin H, Arazo RO, Gao J, Capared S, Chang Z (2014) Leaching of heavy metals from fast pyrolysis residues produced from different particle sizes of sewage sludge. J Anal Appl Pyrol 109:168-175

Jozefaciuk G (2002) Effect of acid and alkali treatments on surface-charge properties of selected minerals. Clays Clay Miner 50(5):647-656

Karami N, Clemente R, Moreno-Jimenez E, Lepp NW, Beesley L (2011) Efiiciency of green waste compost and biochar soil amendments for reducing lead and copper mobility and uptake to ryegrass. J Hazard Mater 191:41-48

Kilic M, Kirbiyik C, Cepeliogullar O, Putun AE (2013) Adsorption of heavy metal ions from aqueous solutions by bio-char, a by-product of pyrolysis. Appl Surf Sci 283:856-862

Kistler RC, Widmer F, Brunner PH (1987) Behavior of chromium, nickel, copper, zinc, cadmium, mercury, and lead during the pyrolysis of sewage sludge. Environ Sci Technol 21:704-708

Kobya M, Demirbas E, Sentruk E, Ince M (2005) Adsorption of heavy metal ions from aqueous solutions by activated carbon prepared from apricot stone. Bioresour Technol 96:1518-1521

Kołodyńska D, Wnętrzak R, Leahy JJ, Kwapiński W, Hayes MHB, Hubicki Z (2012) Kinetic and adsorptive characterization of biochar in metal ions removal. Chem Eng J 197:295-305

Komkiene J, Baltrenaite E (2015) Biochar as adsorbent for removal of heavy metal ions [Cadmium(II), Copper(II), Lead(II), Zinc(II)] from aqueous phase. Int J Environ Sci Technol 13:471-482

Kumar U, Bandyopadhyay M (2006) Sorption of cadmium from aqueous solution using pretreated rice husk. Bioresour Technol 97:104-109

Li H, Dong X, da Silva E, de Oliveira L, Chen Y, Ma L (2017) Mechanisms of metal sorption by biochars: biochar characteristics and modifications. Chemosphere 178:466-478

Liu X, Li J, Huang Y, Wang X, Zhang X, Wang X (2017a) Adsorption, aggregation, and deposition behaviors of carbon dots on minerals. Environ Sci Technol 51:6156-6164

Liu X, Sun J, Duan S, Wang Y, Hayat T, Alsaedi A, Wang C, Li J (2017b) A valuable biochar from poplar catkins with high adsorption capacity for both organic pollutants and inorganic heavy metal ions. Sci Rep 7:10033

Low MJD (1960) Kinetics of chemisorption of gases on solids. Chem Rev 60:267-312

Lu H, Zhang W, Yang Y, Huang X, Wang S, Qiu R (2012) Relative distribution of $\mathrm{Pb}^{2+}$ sorption mechanisms by sludge-derived biochar. Water Res 46:854-862

Lu H, Zhang W, Wang S, Zhuang L, Yan Y, Qiu R (2013) Characterization of sewage sludge-derived biochars from different feedstocks and pyrolysis temperatures. J Anal Appl Pyrol 102:137-143

Malińska K (2012) Biowęgiel odpowiedzią na aktualne problem ochrony środowiska. Inżynieria i ochrona środowiska 15:387-403 (in Polish)
Marczewski A, Szymula M (2002) Adsorption of asphaltenes from toluene on mineral surface. Colloid Surface A 208:259-266

Marczewski AW, Jaroniec M, Deryło-Marczewska A (1986) A new method for characterizing the global adsorbent heterogeneity by using the adsorption data. Mater Chem Phys 14:141-166

Mohamed I, El-Meihy R, Ali M, Chen F, Raleve D (2017) Interactive effects of biochar and micronutrients on faba bean growth, symbiotic performance, and soil properties. J Plant Nutr Soil Sci 180:729-738

Mohan D, Pitmann CU (2006) Activated carbons and low cost adsorbents for remediation of tri- and hexavalent chromium from water. J Hazard Mater 137:762-811

Nessner Kavamura V, Esposito E (2010) Biotechnological strategies applied to the decontamination of soils polluted with heavy metals. Biotechnol Adv 28:61-69

Novak JM, Busscher WJ, Laird DL, Ahmenda D, Watts DW, Niandou MAS (2009) Impact of biochar amendment on soil fertility of a southeastern Coastal Plain soil. Soil Sci 174:105-112

Park JH, Choppala GK, Bolan NS, Chung JW, Cuasavathi T (2011) Biochar reduces the bioavailability and phytotoxicity of heavy metals. Plant Soil 348:439-451

Parker A, Rae JE (2013) Environmental interactions of clays: clays and the environment. Springer, Berlin

Peereboom L (2007) Adsorption of bio-renewable substrates on supported metal catalyst in water. PhD Thesis, Department of Chemical Engineering, Michigan State University, Lansing, Michigan

Pellera FM, Giannis A, Kalderis D, Anastasiadou K, Stegmann R, Wang JY, Gidarakos E (2012) Adsoption of $\mathrm{Cu}(\mathrm{II})$ ions from aqueous solution on biochars prepared from agriculutural byproducts. J Environ Manage 96:35-42

Pendias H, Kabata-Pendias A (1999) Biogeochemia pierwiastków śladowych. PWN, Warszawa (in Polish)

PN-R-04032 (1998) Soils and mineral materials. Soil sampling and granulometric analysis. Polish Committee for Standarization, Warsaw. http://sklep.pkn.pl/pn-r-04032-1998p.html

Ritchie AG (1977) Alternative to the Elovich equation for the kinetics of adsorption of gases on solids. J Chem Soc 73:1650-1653

Sigua GC, Novak JM, Watts DW (2016) Ameliorating soil chemical properties of a hard setting subsoil layer in Coastal Plain USA with different designer biochars. Chemosphere 142:168-175

Sokołowska Z (2011) Specific surface area of soils and plants. In: Gliński J, Horabik J, Lipiec J (eds) Encyclopedia of agrophysics. Springer, Berlin, pp 839-844

Sokołowska Z, Sokołowski S (2008) Fractal approaches to adsorption/desorption processes on environmental surfaces, chapter 6 . In: Senesi N, Wilkinson J (eds) Biophysical chemistry of fractal structures and processes in environmental systems. Wiley, Chichester

Sokołowska Z, Sokołowski S (2011) Adsorption energy and surface heterogeneity in soils. In: Gliński J, Horabik J, Lipiec J (eds) Encyclopedia of agrophysics. Springer, Berlin, pp 2-5

Sokołowska Z, Patrykiejew A, Sokołowski S (1988) Equation for describing anion sorption in soils with their heterogeneous adsorbing surfaces. Geoderma 41:327-336

Sokołowska Z, Sokołowski S, Ouromova-Pesheva A (1993) Adsorption of water vapor by soils: investigations of the influence of organic matter, iron, and aluminum on energetic heterogeneity of soil clays. Clay Clay Miner 41:346-352

Sokołowska Z, Boguta P, Szajdak L (2011) Effect of phosphates on dissolved organic matter release from peat-muck soils. Int Agrophys 2:173-180

Sokołowski S, Sokołowska Z, Warchulska P (2009) Trends in soil fractal parameters caused by accumulation of soil organic matter as resulting from the analysis of water vapour adsorption isotherms. Ecol Complex 6:254-262 
Soudek P, Valesca Rodriguez IM, Petrova S, Song J, Vanek T (2017) Characteristic of different types of biocharand effects on the toxicity of heavy metals to germinating sorghum seeds. J Geochem Explor 182:157-165

Szabó E, Pap Z, Simon G, Dombi A, Baia L, Hernádi K (2016) New insights on the simultaneous removal by adsorption on organoclays of humic acid and phenol. Water 8:21

Taylor RW, Hassan K, Mehadi AA, Shuford JW (1995) Kinetics of zinc sorption by soils. Commun Soil Sci Plant Anal 26:1761-1771

Tong X-j, Li I-y, Yuan J-h, Xu R-k (2011) Adsorption of Cu(II) by biochars generated from three crop straws. Chem Eng J 172:828-834

Uchimiya M, Chang S, Klasson TK (2011a) Screening biochars for heavy metal retention in soil: role of oxygen functional groups. $\mathrm{J}$ Hazard Mater 190:432-441

Uchimiya M, Klasson KT, Wartelle LH, Lima IM (2011b) Influence of soil properties on heavy metal sequestration by biochar amendment: 1. Copper sorption isotherms and the release of cations. Chemosphere 82:1431-1437

Veli S, Alyuz B (2007) Adsorption of copper and zinc from aqueous solutions by using natural clay. J Hazard Mater 149:226-233

Wang Y, Huang H, Duan S, Liu X, Sun J, Hayat T, Alsaedi A, Li J (2018) A new application of a mesoporous hybrid of tungsten

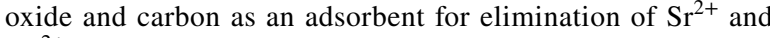
$\mathrm{Co}^{2+}$ from an aquatic environment. ACS Sustain Chem Eng 6:2462-2473

Xu R-k, Zhao A-z (2013) Effect of biochars on adsorption of Cu(II), $\mathrm{Pb}(\mathrm{II})$ and $\mathrm{Cd}(\mathrm{II})$ by three variable charge soils from southern China. Environ Sci Pollut Res 20:8491-8501

Xu X, Schierz A, Xu N, Cao X (2016) Comparison of the characteristics and mechanisms of $\mathrm{Hg}(\mathrm{II})$ sorption by biochars and activated carbon. J Colloid Interface Sci 463:55-60

Yuan JH, Xu RK, Zhang H (2011) The forms of alkalis in the biochar produced from crop residues at different temperatures. Bioresour Technol 102:3488-3497

Zhang S, Zeng M, Li J, Li J, Xu J, Wang X (2014) Porous magnetic carbon sheets from biomass as an adsorbent for the fast removal of organic pollutants from aqueous solution. J Mater Chem A 2:4391-4397

Zhang S, Yang H, Huang H, Gao H, Wang X, Cao R, Li J, Xu X, Wang $X$ (2017) Unexpected ultrafast and high adsorption capacity of oxygen vacancy-rich $\mathrm{WO}_{\mathrm{x}} / \mathrm{C}$ nanowire networks for aqueous $\mathrm{Pb}^{2+}$ and methylene blue removal. J Mater Chem A 5:15913-15922 